\title{
Notas sobre as condições da mão-de-obra feminina frente às inovações tecnológicas
}

\section{A mulher na esfera do trabalho}

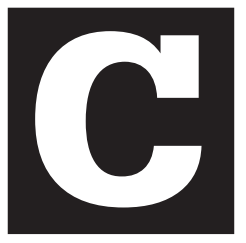

om certeza, o movimento feminista das últimas décadas veio dar um significativo impulso às pesquisas sobre a mulher e sua problemática no mundo contemporâneo. Estudos e reflexões sobre a mulher não são recentes nos escritos de filósofos, teólogos, pedagogos, médicos, juristas, como demonstra a vasta bibliografia compilada por Martin-Gamero (Martin-Gamero, 1975), que registra publicações datadas desde o século XVI, que contemplam as mais diversificadas abordagens da "questão feminina". No entanto, o movimento feminista da segunda metade do século $X X$, ao questionar a discriminação, os tabus, os preconceitos que pesam sobre a mulher e buscar as raízes das práticas que a mantêm sob o domínio masculino, denunciou a especificidade da opressão da mulher em todas as esferas da vida tanto pública quanto privada.

Invadindo os meios acadêmicos, esta abordagem foi decisiva para tornar visíveis os mecanismos que asseguram a reprodução da subordinação da mulher na família e na sociedade, mesmo no contexto da moderna sociedade urbano-industrial, na qual, deve-se reconhecer, grandes avanços já foram conquistados na desmitificação de uma suposta "essência feminina" e da naturalização da condição subordinada da mulher.

Nos estudos sobre as condições de trabalho e de produção, que até então haviam privilegiado particularmente as relações e conflitos entre ca- 
pital e trabalho, a grande contribuição dos estudos acadêmicos realizados a partir da especificidade da problemática feminina foi demonstrar que a classe operária tem dois sexos, levando à superação da concepção da classe como um coletivo assexuado, no qual homens e mulheres são, indistintamente, oprimidos e explorados pelo capital. A abordagem das relações de classe para a reconstrução interpretativa dos mecanismos de reprodução da submissão do trabalho ao capital foi enriquecida pela abordagem a partir das relações sociais de sexo, que possibilita ampliar a visibilidade das estratégias de controle e exploração do capital, diversamente operacionalizadas para cada categoria de trabalhadores, no caso que aqui nos interessa, as mulheres.

É oportuno fazer um parênteses para lembrar que a consideração da classe trabalhadora, não como um todo homogêneo, mas como um coletivo segmentado por diversos atributos que a diferenciam internamente como raça, etnia, cultura, nacionalidade, condição legal (ex: trabalhadores clandestinos, cf. Linhart, 1986) - tem sido decisiva para desnudar as inumeráveis estratégias do capital para explorar o trabalho.

A abordagem da classe trabalhadora como portadora de atributos sexuais distintos permitiu revelar a articulação capitalismo/patriarcalismo, que assegura, simultaneamente, a sobreexploração da mulher pelo capital e sua subordinação ao poder masculino, reproduzido na família e na sociedade.

O conceito de relações sociais de gênero fez avançar na compreensão da complexidade dessa articulação. Considerando-se que as relações entre homens e mulheres são relações sociais que implicam a) antagonismo ou conflito ligados a relações de dominação e opressão; b) organização social sistemática que atravessa o conjunto da sociedade e se articula com o resto das relações sociais e c) são historicamente transformáveis (Varikas, 1992), o conceito permite desnaturalizar uma série de fenômenos históricos e superar a abordagem limitadora da consideração estritamente biológica como fundamento das diferenças entre homens e mulheres. Dessa for- 
ma, o fundamento social dessas diferenças aponta no sentido de interpretálas como desigualdades, enraizadas nas concepções e práticas culturais do que é definido como "ser homem" e "ser mulher" em cada contexto particular, e por isso, passíveis de diferentes configurações e conteúdos concretos e simbólicos.

No entanto, apesar do amplo leque dessas configurações, um dado pode ser considerado universal: o de que as funções prioritárias da mulher são sua dedicação à esfera doméstica e o desempenho de tarefas que assegurem a manutenção e a reprodução do grupo familiar, e que comportam, em cada contexto sociocultural, a produção de bens e de serviços bastante diferenciada (por exemplo, o conteúdo do trabalho doméstico no meio rural e na cidade).

A partir desta perspectiva, o trabalho da mulher fora do âmbito doméstico, executado em troca de salário, chegou a ser considerado como um fenômeno passageiro, provocado por fatores conjunturais (p.ex. queda geral dos salários, compelindo outros membros da família - a mulher e mesmo as crianças - além do homem, tido como seu "natural provedor", a ingressarem no mercado de trabalho), os quais, quando superados, restabeleceriam a natural divisão do trabalho entre homens e mulheres. Argumentos tão severos quanto o de que a saída da mulher do âmbito doméstico poderia levar à degradação da espécie foram usados para se opor ao seu ingresso na produção social. A denúncia de que os prejuízos para a mulher que trabalha decorrem não do trabalho em si mesmo, mas do modo como é socialmente organizado, já era veiculada no início do século XX (Gonnard, 1906; Maday, 1905), num contexto de crítica às condições de exploração do trabalho pelo capital, que penalizavam as mulheres mais ainda que os homens. Com freqüência, esta posição estava associada à defesa do direito da mulher ao trabalho como condição necessária, ainda que não suficiente, à sua emancipação.

À luz do exame de séries estatísticas referentes à grande maioria dos países do mundo, o ponto de vista de que a presença da mulher na produ- 
ção social seria um fenômeno eventual e passageiro é fragorosamente refutado: a persistente tendência de aumento do número de mulheres integradas ao mercado de trabalho permite considerá-la como um fato irreversível. A proporção da população feminina na faixa etária dos 15 aos 64 anos, integrada no mercado de trabalho em quase todos os países desenvolvidos, aumentou significativamente entre 1970 e 1990: nos Estados Unidos, de 48,9\% para 69,1\%; no Japão, de 55,4\% para 61,8\%; na Espanha, de 29,2\% para $42,8 \%$ (Castells, 1999, p. 274). No Brasil, essa proporção (mulheres com 10 anos e mais) era de 47,2\% em 1997 (IBGE, 1999). A participação feminina na PEA brasileira, que era de 14,6\% em 1950, elevou-se para 20,9\% em 1970, segundo os censos demográficos, alcançando 40,4\% em 1997 (IBGE, 1999).

Estudos sobre a estrutura ocupacional, por sexo, realizados em diversos países, têm mostrado uma recorrência na sua configuração: enquanto a mão-de-obra masculina se distribui em todos os ramos da atividade industrial e nas ocupações do setor terciário, as mulheres se concentram em algumas poucas categorias ocupacionais (Bradley, 1989), constituindo o que se poderia chamar guetos femininos no mercado de trabalho. Nas sociedades industrializadas, a mão-de-obra feminina se concentra nas indústrias de alimentos, têxteis, de confecção e de calçados e, mais recentemente, na eletrônica. No setor terciário, as mulheres estão ocupadas, predominantemente, no comércio, nos escritórios e nos serviços profissionais de educação, saúde e bem-estar. Estudos de categorias profissionais ou que tomam como objeto um determinado local de trabalho (fábrica, banco, estabelecimento comercial) revelam uma outra forma de segregação, vertical (Silva, 1985; Bradley, 1989), que atua sobre a mão-de-obra feminina, pela qual ela se concentra nos níveis mais baixos da hierarquia técnica, funcional e salarial na estrutura das empresas ou nas categorias ocupacionais. Em especial na indústria, as tarefas reservadas às mulheres são, via de regra, as consideradas mais leves, mais simples e, inegavelmente, as mais repetitivas e mais monótonas, que requerem mais paciência e execução mais minuci- 
osa, porque, explícita ou tacitamente, elas são entendidas como mais adequadas às aptidões consideradas inerentes à mão-de-obra feminina. Sistematicamente, essas tarefas são também consideradas não qualificadas. Para Kergoat, a classificação das qualificações, assim como as decisões que orientam as promoções, cujos critérios jamais são plenamente explicitados pelos empregadores, corresponde a uma hierarquização ideológica (Kergoat, 1982), a partir da qual cada trabalho é diferentemente valorizado, cada trabalhador é mais ou menos considerado socialmente do que os demais, ao que se associa uma correspondente hierarquização da remuneração.

As aptidões mais reconhecidas como características da mão-de-obra feminina como agilidade, destreza e rapidez, louvadas por muitos empregadores ("as mulheres têm dedos de fadas e manipulam melhor os minúsculos componentes eletrônicos" ou "a habilidade da mão de uma operária que executa trabalhos finos é simplesmente demoníaca") (Kergoat, 1982, p.54), não são admitidas como qualificações adquiridas, mas como dons inatos, "como fatos da natureza e não como fatos da cultura" (Kergoat, 1982, p.55), o que serve para sustentar sua exclusão das categorias de trabalhadores qualificados. Associadas com padrões comportamentais considerados típicos da mão-de-obra feminina como paciência, perspicácia, fidelidade, maior aceitação de trabalhos enfadonhos e resistência à monotonia, que resultam em maior docilidade à dominação do capital, aquelas qualificações tácitas, preciosas para o empregador, mas desvalorizadas socialmente, asseguram uma superexploração da mão-de-obra feminina. Observando a importância daquelas qualificações para o desempenho satisfatório de um grande número de tarefas em distintos ramos industriais, em São Paulo, Rodrigues acredita ter encontrado significativos reforços para a idéia de que a mulher não constitui, na indústria, um exército de reserva, já que, para algumas tarefas, ela é, realmente, insubstituível (Rodrigues, 1992).

Essas condições, observadas no setor industrial, convivem com o ingresso continuado de mulheres em ocupações que requerem maior qualificação profissional. No Brasil, tem-se verificado um aumento rápido da 
presença de mulheres em ocupações de nível superior como medicina, odontologia, veterinária, arquitetura, engenharia, que eram consideradas ocupações masculinas. Isto se deve à elevação do padrão da escolarização feminina, superando o dos homens, fenômeno observado também em outros países. Aqui, as mulheres são a maioria dos alunos matriculados da $8^{\mathrm{a}}$ série do ensino fundamental em diante. No ensino superior, são 54\% dos estudantes (MEC/INEP, 1998). Os reflexos deste processo se manifestam no padrão de escolaridade da PEA no país: 23,2\% das mulheres que a integram têm 11 anos ou mais de escolaridade, enquanto entre os homens essa proporção é de apenas 16,3\% (IBGE/PNAD, 1999).

Apesar destas mudanças favoráveis, muitas das desvantagens que as mulheres enfrentam no mercado de trabalho não foram superadas.

\section{Novas tecnologias e mão-de-obra feminina}

O processo de reestruturação produtiva em curso comporta uma série de estratégias em resposta à situação de crise do capitalismo, delineada a partir dos anos 70 (Clarke, 1991; Navarro 1993; Katz, 1991; Rojas, 1987).

O acirramento da competição internacional e a crescente resistência dos trabalhadores à organização da produção estão na raiz dessa crise. A resposta do capital aparece na forma de uma nova onda de inovações tecnológicas, de base microeletrônica, associada à descentralização produtiva e à desregulamentação das relações laborais. As conquistas trabalhistas que asseguraram, em muitos países, ao longo do século XX, considerável poder de negociação aos trabalhadores, vão sendo suprimidas, e formas mais flexíveis de contratação e uso da força de trabalho vão-se expandindo, como a subcontratação, o trabalho temporário, o trabalho em tempo parcial. A descentralização produtiva se efetiva com a migração do capital para regiões, dentro das fronteiras nacionais ou localizadas em outros países, onde a garantia de rápido retorno dos investimentos é anunciada pela exis- 
tência de uma força de trabalho numerosa, barata e debilmente organizada. A chegada dos capitais investidos é brindada com medidas que flexibilizam as condições de instalação das empresas e colaboram na criação de condições favoráveis à exploração da mão-de-obra. A utilização de novas tecnologias, entendidas não só como equipamentos de base microeletrônica, mas também como novos métodos de gerenciamento da produção e do processo de trabalho (Montero, 1989), em geral inspirados no chamado "modelo japonês", pode ou não estar presente, dependendo da apreciação do capital sobre as vantagens ou não de seu emprego.

As conseqüências, para a mão-de-obra feminina, da implantação dessas estratégias têm sido registradas em inúmeros estudos de casos, que revelam a diversidade de situações em que a mulher é empregada pelo capital, nas quais um elemento comum é a condição de desvalorização dessa mão-de-obra, sua concentração em níveis inferiores quanto à qualificação, à valorização das tarefas e à remuneração, e sua subordinação à autoridade masculina no local de trabalho.

Esses estudos também têm apontado que a introdução da microeletrônica tem, quase sempre, aprofundado a cisão entre o trabalho desqualificado das mulheres e o trabalho requalificado demandado pelas novas tecnologias, executado pelos homens (Abreu, 1993). Além disso, em alguns setores, as tarefas que mais rapidamente estão sendo informatizadas são as classificadas na base da escala de qualificações, exatamente onde a mão-de-obra feminina está concentrada. A expectativa alimentada nos anos 60 de que a informatização tenderia a criar condições de maior igualdade para homens e mulheres no mercado de trabalho bem como melhores oportunidades de remuneração e promoção para as mulheres, está hoje desfeita. As novas qualificações demandadas não têm, de modo relevante, aberto caminhos de ascensão para as mulheres.

Analisando a presente organização em rede da economia mundializada, Castells aponta a predominância de mulheres e jovens nas empresas periféricas da rede, nas quais elas constituem uma mão-de-obra 
considerada dispensável e facilmente substituível, empregada em caráter temporário ou como trabalhadores em tempo parcial (Castells, 1999, p.195). Na mais avançada configuração econômica e social contemporânea, as condições de desvantagem da mulher continuam presentes.

Em décadas recentes, o movimento de migração de capitais dos países centrais tem-se orientado para alguns países da Ásia, nos quais foi rapidamente implantado um expressivo setor industrial voltado para a exportação. Têxteis, confecções, calçados, produtos e componentes eletrônicos são ramos destacados na industrialização recente dos chamados tigres asiáticos.

Um conjunto de estudos realizados em doze países da Ásia - Laos, China, Hong Kong, Coréia do Sul, Taiwan, Singapura, Malásia Sri Lanka, Tailândia, Indonésia, Filipinas e Bangladesh - apontou que, apesar da diversidade de estratégias conjugadas das autoridades locais e das firmas estrangeiras que investiram em cada um desses países (Heyzer, 1988), com exceção do Paquistão ${ }^{1}$, todos os casos têm em comum a integração de grandes contingentes de mulheres às atividades industriais. Em geral, são mulheres jovens, recrutadas no meio rural, sem experiência de trabalho industrial, socializadas numa tradição de rigorosa submissão à autoridade no seio da família, o que as torna dóceis à autoridade, sempre masculina, que encontram dentro das fábricas. As políticas de gestão da mão-de-obra aí praticadas se sustentam nos padrões culturais tradicionais locais. No entanto, o incentivo a padrões comportamentais "modernos" não é descartado pelo capital, quando podem produzir efeitos positivos à sua dominação.

Num estudo realizado na indústria eletrônica na Malásia (onde 95\% da mão-de-obra empregada são mulheres), foi verificado que um novo estereótipo feminino se estava difundindo, estimulado pelas gerências das empresas, pelo qual a mulher passava a ser valorizada como objeto sexual

\footnotetext{
1 Nesse país, de forte tradição islâmica, as mulheres ainda estão submetidas à reclusão, e sua participação no mercado de trabalho industrial assalariado era pouco significativa em 1981: apenas 5,9\%. Em Bangladesh, outro país islâmico, as mulheres representavam, em 1984, 28\% da força de trabalho industrial, graças a uma campanha de recrutamento de mão-de-obra nas áreas rurais, que transferiu para as fábricas cerca de 80 a 100 mil jovens mulheres (Heyzer, 1988).
} 
e como consumidora (Cardosa-Khoo e Jin-Khoo, 1989). A realização desse ideal depende do salário que recebe como operária e que dá acesso ao mercado de produtos requeridos pelo padrão moderno e desejável de mulher. Outras estratégias de integração são postas em prática para fazer com que as jovens operárias se sintam parte da grande família que a empresa deve ser e se submetam às duras condições de trabalho que lhes são impostas. O consumo de anfetaminas, admitido como usual pelas próprias operárias, e a alta incidência de acidentes de trabalho são indicadores apontados pelas autoras, das pressões e constrangimentos a que estão submetidas as mulheres. O estímulo à competição entre elas dissipa qualquer possibilidade de desenvolver formas de solidariedade e de organização que pudessem levá-las a reivindicar a reversão da situação vivida. Além disso, tal tipo de conduta seria socialmente inaceitável.

No entanto as autoras verificaram um tipo de incidente que ocorria com freqüência e que elas traduziram como uma forma de resistência pela qual as operárias descarregam as tensões acumuladas no cotidiano da fábrica. Tais incidentes, chamados masuk hantu, são atribuídos a espíritos que se apossam das mulheres e "começam como explosão histérica de uma operária, freqüentemente seguida de um surto de histeria através da fábrica (...) que tem que fechar por um dia, às vezes por mais tempo, para dar tempo às mulheres para se recuperarem" (p.212). Não há reprovação a esse tipo de comportamento, pelo qual são responsabilizados espíritos perturbadores. Uma grande empresa americana, violentamente atingida por um incidente desse tipo, contratou um curandeiro (tradicional medicine man) para exorcizar os espíritos que encarnavam nas operárias. Algumas empresas chegaram a fazer oferendas para que eles não retornassem. As operárias mais vulneráveis a esses acessos eram as que trabalhavam com microscópios, em tarefas particularmente estressantes. As gerências das empresas, ao endossarem crenças e práticas culturais locais como explicação e tratamento para o descontrole das jovens, isolava as condições de trabalho como causa do fenômeno, protegendo-se de um eventual 
questionamento daquelas condições.

Outros estudos verificaram também que sistemas de punição para operárias consideradas indisciplinadas ou relapsas, ou com dificuldades para cumprir as metas de produção impostas, são também freqüentes e, em geral, mais rigorosas, humilhantes e constrangedoras nas ZPEs, onde não há organização operária ou ela é muito débil (Goodetilahe e Goonesekere, 1988).

Pesquisas realizadas em países não asiáticos revelam, nas suas especificidades, as condições desfavoráveis em que a mulher se integra ao mercado de trabalho. No México, o crescimento industrial em sua fronteira norte tem incorporado grandes contingentes de mulheres nas grandes firmas maquiladoras, nos trabalhos mais banalizados nas empresas de confecção, calçados e eletrônica, ou em pequenas oficinas subcontratadas, nas quais a remuneração é muito baixa e os direitos trabalhistas inexistentes (Pearson, 1989; Oliveira e Garcia, 1988).

Não se pode negar, no entanto, que, mesmo num quadro de persistência de desvantagens na integração da mulher no mercado de trabalho, alguns casos registram melhores oportunidades de ascensão a posições mais qualificadas e socialmente mais valorizadas. Foi o que observaram Cockburn, na Inglaterra, no setor de radiologia computadorizada (Cockburn, 1985), e Larangeira, num banco estatal no Rio Grande do Sul, no setor de programação (Larangeira, 1992) ou ainda na presença crescente em ocupações socialmente prestigidas, antes desempenhadas apenas por homens. Esses casos parecem ser, pelo menos por enquanto, a exceção e não a regra.

\section{Considerações finais}

As novas tecnologias de base microeletrônica e as novas formas de gerenciamento da produção e do trabalho que informam o presente processo de reestruturação produtiva não têm apontado uma tendência de 
reduzir a segregação da mulher no mercado de trabalho e melhorar substancialmente sua posição na hierarquia técnica, salarial e de qualificações na estrutura interna das empresas e das ocupações. Ao contrário, o que os dados estatísticos e os estudos de caso têm revelado é uma tendência a aprofundar a trincheira que separa trabalhadores não qualificados/não valorizados - majoritariamentre mulheres - dos trabalhadores qualificados/valorizados - predominantemente homens (Abreu, 1993).

O crescente ingresso das mulheres no mercado de trabalho, fenômeno de abrangência quase universal, tem ocorrido predominantemente em situação periférica (Castells, 1999), em ocupações mal remuneradas, banalizadas pela fragmentação das tarefas ou pela automação ou sob condições de desregulamentação das relações de trabalho ${ }^{2}$, obstaculizando as expectativas de ascensão alimentada nos anos 60.

A persistência de relações de dominação no seio da família e na sociedade, recriadas com novas roupagens em contextos de rápidas transformações econômicas e culturais, baliza essa tendência. A máquina a vapor, prescindindo da força física dos trabalhadores, permitiu incorporar um grande contingente de mulheres - e de crianças - à produção fabril, sem dar-lhes oportunidades de se equipararem aos homens em relação aos ganhos (já por si pouco invejáveis) e às oportunidades de ascensão profissional. Isto por que a máquina a vapor foi o resultado de uma forma histórica de organizar a produção, cujo pressuposto e sentido é a exploração e a dominação de uns poucos sobre a grande maioria, utilizando-se dos diferentes atributos desta maioria para obter ganhos adicionais de rentabilidade. Para tanto, contribuiu o estigma das diferenças naturalizadas, construídas e sedimentadas na família e na sociedade. Assim também as novas tecnologias de base microeletrônica não têm o poder mágico de subverter estruturas de dominação que perpassam todo o tecido social, ou de erradicar crenças e práticas nas quais o patriarcalismo se mantém, articulado com o capital

2 No Brasil, as mulheres estão em melhores condições que os homens no que diz respeito à formalização das relações de trabalho, pois $68,4 \%$ da PEA feminina trabalha com carteira assinada. Entre os homens, a proporção é de 60,4\%. Em alguns estados, a diferença a favor das mulheres supera dez pontos percentuais (IBGE/PNAD, 1989). 
para duplamente explorar as mulheres.

\section{Referências bibliográficas}

ABREU, Alice R.P. Mudanças tecnológicas e gênero no Brasil. Novos Estudos, São Paulo, n.35, mar. 1993.

BRADLEY, Harriet. Men`s work, women`s work. Cambridge (UK), Polity Press, 1989.

CASTELLS, Manuel. A sociedade em rede. Rio de Janeiro, Paz e Terra, 1999.

CARDOSA-KHOO, Jane and JIN KHOO, Khay. Work and consciousness: women workers in the electronic industry in Malaysia. In: YOUNG, Kate (Ed.). Serving two masters. Third world women in development. New Delhi, Allied Publishers Lt, 1989.

CLARKE, Simon. Crise do fordismo ou crise da social democracia? Lua Nova, São Paulo, n.24, set. 1991.

COCKBURN, Cynthia. Machinery of dominance. Women, men and technical know how. London, Pluto Press, 1985.

GOONATILAKE, Hema; GOOESEKERE. Savitri. Industrialisation and women workers in Sri Lanka: work conditions inside and outside the investment promotion zone. In: HEYZER, Noeleen (Ed.). Daugthers in industry. Kuala Lumpur, APDC, 1988. GONNARD, R. La femme dans I'industrie. Paris, Librairie Armand Colin, 1906. HEYZER, Noeleen. Daughters in industry. Work skills and consciousness of women workers in Asia. Kuala Lumpur, APDC (Introduction), 1988.

IBGE/PNAD. Sìntese de indicadores sociais. Rio de Janeiro, 1999.

KATZ, Claudio. Nuevas y viejas tecnologias en América Latina. Problemas de desarrollo. Revista Latinoamericana de Economia, México, v.22, n.84, 1991. KERGOAT, Danièle. Les ouvrières. Paris, Le Sycomore, 1982.

LARANGEIRA, Sonia. Notas sobre a informatização dos serviços bancários. Porto Alegre, UFRGS, 1992. (paper)

LIEDKE, Elida Rubini. Diferenciação da força de trabalho na empresa. Um estudo de caso na indústria eletrônica. Cadernos de Sociologia,. Porto Alegre, PPGS/ UFRGS, 1989.

LINHART, Robert. Greve na fábrica. 3.ed. Rio de Janeiro, Paz e Terra, 1986. 
MADAY, André. Le droit des femmes au travail. Genève, Atar AS, 1905. MARTIN-GAMERO, Amalia. Antología del feminismo. Madrid, Alianza Ed., 1975. MEC/INEP. Censo Escolar de 1988. Brasília, 1988.

MONTERO, Cecilia. Cambio tecnológico, empleo y trabajo. OIT - Programa regional del empleo para América Latina y el Caribe. Documentos de Trabajo, Santiago do Chile, n.333, 1989.

NAVARRO, Vicente. Produção e estado de bem-estar: o contexto político das reformas. Lua Nova, São Paulo, n.28-29, 1993.

OLIVEIRA, Orlandina e GARCIA, Brígida. Fuerza de trabajo femenina y transformación social en México. Porto Alegre, VIII Seminário de Estudos Latinoamericanos, 1988. (paper)

PEARSON, Ruth. Women works in Mexico's border industries. In: YOUNG, Kate (Ed.). Serving two masters. Third world women in development. New Delhi, Allied Publishers Lt., 1989.

RODRIGUES, Arakcy Martins. Lugar e imagem da mulher na indústria. In: COSTA, Albetina de Oliveira; BRUSCHINI, Cristina. Uma questão de gênero. Rio de Janeiro, Rosa dos Tempos; São Paulo, Fundação Carlos Chagas, 1992.

SILVA, Lorena Holzmann da. Mulheres trabalhadoras - problemas e conquistas. Cadernos de Estudos, Porto Alegre, n.15, 1985.

UFRGS. Quem são os alunos da UFRGS. Fascículos PROGRAD, Porto Alegre, n.12, 1988.

VARIKAS, Eleni. Quelques reflexions en vrac à propos de l'usage de 'genre' rapports sociaux de sexe et division sexuelle du travail. Cahiers du GEDISST, Paris, Iresco/ CNRS, 1992. 


\section{Resumo}

As novas tecnologias de base microeletrônica e as novas formas de gerenciamento da produção e do trabalho, que caracterizam a reestruturação produtiva em curso, não têm reduzido, de modo significativo, a situação desvantajosa da mulher no mercado de trabalho, na hierarquia técnica, salarial e de qualificações no interior das empresas e das ocupações. Este artigo, analisando as condições de inserção crescente das mulheres na produção social, conclui que a persistência de relações sociais que mantém as mulheres subordinadas aos homens no seio da família e na sociedade, tem sido determinante na manutenção daquelas desvantagens, ainda que melhorias de oportunidades possam ser verificadas. Neste caso, elas são resultado de transformações nas relações sociais de gênero, e não conseqüência das inovações tecnológicas e gerenciais.

Palavras chave: Novas tecnologias; trabalho feminino; relações de gênero 